\title{
Canadian parents' attitudes and beliefs about bicycle helmet legislation in provinces with and without legislation
}

\author{
P. C. Parkin, MD (1, 2, 3); J. DeGroot, MSc (1, 2); A. Macpherson, PhD (4); P. Fuselli, MSc (5); \\ C. Macarthur, MBChB $(1,2,3)$
}

This article has been peer reviewed.

\begin{abstract}
Introduction: The objective of this study was to survey Canadian parents on their attitudes and beliefs about bicycle helmet legislation and to compare responses from parents living in provinces with and without legislation.
\end{abstract}

Methods: A national survey of 1002 parents of children aged under 18 years was conducted. Chi-square tests were used to compare responses from the surveyed parents in the different jurisdictions.

Results: Responses from parents living in provinces with legislation $(\mathrm{n}=640)$ and without legislation $(\mathrm{n}=362)$ were as follows: concern for injury ( $63 \% \mathrm{vs.} 68 \%$, nonsignificant [NS]); believe helmets are effective ( $98 \%$ vs. $98 \%$, NS); child always wears a helmet ( $74 \%$ vs. $69 \%$, NS); support legislation for children $95 \%$ vs. $83 \%$, $p<.001)$; support legislation for all ages ( $85 \%$ vs. $75 \%, p<.001)$; support police enforcement ( $83 \%$ vs. $76 \%, p=.003$ ); believe legislation decreases the amount of time their child bicycles ( $5 \%$ vs. $8 \%$, NS).

Conclusion: Parents are highly supportive of bicycle helmet legislation in Canada. They believe that bicycle helmets are effective and that legislation does not decrease the amount of time a child spends bicycling. There was also a high level of support for legislation across all ages, and for police enforcement.

Keywords: helmets, legislation, surveys, child, attitude, public health, head protective devices, bicycle

\section{Introduction}

Systematic reviews have shown that wearing bicycle helmets reduces the risk of head, brain and facial injuries and that helmet legislation increases helmet use and decreases head injury rates. ${ }^{1-3}$ Many jurisdictions in Canada (6 out of 10 provinces) have legislated helmet use, and some municipalities have adopted more rigorous and universal legislation. ${ }^{4}$
Despite the supporting evidence, debate about the advantages of helmet use and helmet legislation continues. ${ }^{5,6}$ This debate has not, however, included a societal perspective.

The objective of our study was to survey Canadian parents about their attitudes and beliefs towards bicycle helmet legislation and to compare responses from parents living in provinces with and without legislation.

\section{Methods}

We designed our survey to examine several currently debated issues from the perspective of Canadian parents. The questions related to parents' perceptions of the effectiveness of bicycle helmets, their support for bicycle helmet legislation and enforcement and their perceptions of the effect of legislation on bicycle use. Additional demographic questions included age and sex of their child, age and education of the responding parent, family income and the province where the family lived. The survey was conducted from 1 February 2010 to 5 February 2010. The sampling frame was Canadian adults aged 18 years and over who were members of the LegerWeb online panel. ${ }^{*}$ This national online panel, which is used to conduct over 1000 surveys per year in Canada, consists of about 345000 members, with between 10000 and 20000 new members added each month and a retention rate of $90 \%$. Invitations to new panelists are made to ensure representativeness of the entire adult population in Canada by sex, age, income and region. To enhance participation, respondents are entered into monthly draws for prizes. For this study, panel members with children under the age of 18 years were randomly selected to receive an email invitation to the survey.

A sample size of 1000 was sufficient to determine the single proportion of all respondents supporting legislation with a

1. Division of Paediatric Medicine and the Paediatric Outcomes Research Team (PORT), Hospital for Sick Children, Toronto, Ontario, Canada 2. Child Health Evaluative Sciences, Hospital for Sick Children, Toronto, Ontario, Canada

3. Department of Pediatrics and Institute of Health Policy, Management and Evaluation, University of Toronto Faculty of Medicine, Toronto, Ontario, Canada

4. School of Kinesiology and Health Science, York University, Toronto, Ontario, Canada

5. Safe Kids Canada, Toronto, Ontario, Canada

Correspondence: Patricia Parkin, Division of Pediatric Medicine and the Pediatric Outcomes Research Team, Hospital for Sick Children, 555 University Avenue, Toronto, ON M5G 1X8; Tel.: 416-813-6933; Fax: 416-813-5663; Email: patricia.parkin@sickkids.ca 
margin of error of $\pm 3 \%$ with $95 \%$ confidence and to provide $90 \%$ power to detect a difference of $10 \%$ between respondents living in provinces with and without legislation. We used descriptive statistics to describe responses from the entire survey population and chi-square tests to compare responses from those living in provinces with and without legislation. We used Bonferroni correction to account for multiple comparisons (adjusted $p<.004$ considered significant). We also conducted an exploratory analysis of the responses of those living in provinces with all-ages bicycle helmet legislation and those living in provinces with child-only legislation.

Ethics approval for the study was given by the Hospital for Sick Children Research Ethics Board.

\section{Results}

Of 1128 parents invited to join the survey, 1002 responded ( $89 \%$ response rate), 640 from provinces with legislation (155 with all-ages legislation and 485 with child-only legislation) and 362 from provinces without. Only $3.6 \%$ of respondents indicated that their child or children had ever had a bicycle injury requiring medical attention. The characteristics of the parent respondents and their children are shown in Table 1. The proportion of respondents with a household income between $\$ 50000$ and $\$ 125000$ (53\%, 95\% confidence interval $[\mathrm{CI}]: 50 \%-56 \%$ ) is similar to the national census for family income $(51 \%) .^{7}$ The proportion of respondents who attained a university education (50\%, $95 \%$ CI: $47 \%-53 \%$ ) is higher than the national census for adults aged 25 to 64 years $(23 \%))^{8}$ The proportion of respondents by province was similar to population density by province according to national census data. ${ }^{9}$

Responses to various issues from parents living in provinces with and without legislation, respectively, were as follows: concern about injury (63\% vs. 68\%, nonsignificant [NS]); believe helmets are effective ( $98 \%$ vs. $98 \%$, NS); child always wears a helmet (74\% vs. $69 \%$, NS); support childonly legislation $(95 \%$ vs. $83 \%, p<.001)$; support all-ages legislation ( $85 \%$ vs. $75 \%$,
TABLE 1

Survey participant characteristics $(\mathrm{N}=1002)$

\begin{tabular}{|c|c|c|}
\hline Demographics & n & $(\%)$ \\
\hline \multicolumn{3}{|l|}{ Parent age, years } \\
\hline$<35$ & 375 & (37.4) \\
\hline $35-44$ & 467 & $(46.6)$ \\
\hline$\geq 45$ & 160 & $(16.0)$ \\
\hline \multicolumn{3}{|l|}{ Sex of surveyed parent } \\
\hline Male & 465 & $(46.4)$ \\
\hline \multicolumn{3}{|l|}{ Parent education attained } \\
\hline High school / college & 492 & $(49.1)$ \\
\hline University & 500 & (49.9) \\
\hline Prefer not to answer & 10 & (1.0) \\
\hline \multicolumn{3}{|l|}{ Household income, \$ } \\
\hline$<50000$ & 178 & (17.8) \\
\hline 50 000-124999 & 528 & (52.7) \\
\hline$\geq 125000$ & 160 & $(16.0)$ \\
\hline Don't know / prefer not to answer & 136 & (13.6) \\
\hline \multicolumn{3}{|l|}{ Child age, years ${ }^{\mathrm{a}}$} \\
\hline$<1$ & 138 & (6.8) \\
\hline $1-4$ & 829 & $(40.8)$ \\
\hline $5-9$ & 777 & $(38.2)$ \\
\hline $10-14$ & 217 & (10.7) \\
\hline $15-17$ & 72 & (3.5) \\
\hline \multicolumn{3}{|l|}{ Sex of children } \\
\hline Male only & 292 & $(29.1)$ \\
\hline Female only & 286 & $(28.5)$ \\
\hline Both male and female & 414 & $(41.3)$ \\
\hline Prefer not to answer & 10 & $(1.0)$ \\
\hline \multicolumn{3}{|l|}{ Province } \\
\hline British Columbia & 100 & $(10.0)$ \\
\hline Alberta & 85 & (8.5) \\
\hline Saskatchewan & 28 & (2.8) \\
\hline Manitoba & 57 & (5.7) \\
\hline Ontario & 400 & (39.9) \\
\hline Quebec & 267 & (26.7) \\
\hline New Brunswick & 31 & (3.1) \\
\hline Prince Edward Island & 1 & $(0.1)$ \\
\hline Nova Scotia & 23 & (2.3) \\
\hline Newfoundland and Labrador & 10 & (1.0) \\
\hline \multicolumn{3}{|c|}{ Child has had bicycle injury requiring medical attention } \\
\hline Yes & 36 & (3.6) \\
\hline No & 957 & $(95.5)$ \\
\hline Don't know / prefer not to answer & 9 & (0.9) \\
\hline
\end{tabular}

a The total number of children is greater than the number of participants because there are multiple children in families $(n=2033)$.

$p<.001)$; support police enforcement ( $83 \%$ vs. $76 \%, p=.003)$; believe legislation decreases the amount of time their child bicycles ( $5 \%$ vs. $8 \%$, NS).
Responses from parents living in provinces with all-ages legislation and childonly legislation, respectively, were as follows: concern about injury $(68 \%$ vs. 
$61 \%$ ); believe helmets are effective (96\% vs. 99\%); child always wears a helmet (77\% vs. $73 \%$ ); support child-only legislation $(97 \%$ vs. $94 \%)$; support all-ages legislation (91\% vs. $84 \%$ ); support police enforcement ( $89 \%$ vs. $82 \%)$; believe legislation decreases the amount of time their child bicycles ( $6 \%$ vs. $5 \%$ ). None of these comparisons were statistically significant (at the $p<.004$ level).

\section{Discussion}

This national sample of Canadian parents living in provinces with and without bicycle helmet legislation has shown that many parents believe that bicycle helmets are effective and that legislation does not decrease the amount of time a child spends bicycling; there was also a high level of support for legislation across all ages and for police enforcement of this legislation.

An earlier survey, conducted in a Canadian city in 1991 prior to legislation, demonstrated $80 \%$ support for legislation. ${ }^{10}$ This is similar to the rate of support that we found among parents living in provinces without legislation. The current $93 \%$ rate of support from parents living in provinces with legislation indicates a substantial increase over the past two decades.

Four of the 10 Canadian provinces (British Columbia, New Brunswick, Prince Edward Island and Nova Scotia) have all-ages helmet legislation; Alberta and Ontario have legislation for bicyclists aged less than 18 years; and the remaining provinces (Saskatchewan, Manitoba, Quebec, Newfoundland and Labrador) and the three territories (Yukon, Northwest Territories and Nunavut) have no legislation. This variety provides information for a natural experiment examining helmet use and beliefs. A recent analysis of data from the Canadian Community Health Survey found that self-reported bicycle helmet use in youth (12-18 years) increases as helmet legislation becomes more comprehensive: $33 \%$ in provinces with no legislation; $47 \%$ in provinces with child-only legislation; and $78 \%$ in provinces with all-ages legislation. ${ }^{11}$ In our predominately pre-adolescent age group ( $86 \%$ were under the age of 10 years), comprehensiveness of the legisla- tion was associated with parent-reported support of legislation (both child-only and all-ages) and police enforcement, but not with parent-reported child helmet use rates.

Ontario, one of the two provinces with child-only legislation, has debated whether to introduce all-ages legislation. In June 2012, the Office of the Chief Coroner $^{12}$ reported on their review of all 129 cycling deaths in Ontario between 2006 and 2010. Of these, $15 \%$ were aged 19 years or less and only $27 \%$ were wearing a helmet. The report recommended amending the Highway Traffic Act to make helmets mandatory for cyclists of all ages. ${ }^{12}$ The results of our survey suggest that parents would strongly support this recommendation.

The ongoing debate about the potential benefit and harm of bicycle helmet legislation includes a concern that “....enforced laws discourage cycling, increasing the costs to society of obesity and lack of exercise and reducing overall safety of cycling...,"13,p86 However, direct observations of bicycling children in one Canadian city yearly between 1993 and 1999 found that the introduction of helmet legislation did not significantly affect the numbers of hours that children cycled. ${ }^{14}$ In addition, our survey found that only $5 \%$ of parents who lived in a province with bicycle helmet legislation reported that this legislation decreased the amount of time their child cycled. Together, these studies of directly observed and parent-reported child behaviours suggest that legislation has promoted safety without reducing physical activity.

\section{Limitations}

A limitation of this survey is the higher educational attainment of the parent respondents as compared with the national census. Nevertheless, that $70 \%$ of the parents surveyed reported that their child(ren) always wore a helmet is consistent with direct observational studies of bicyclists in Canadian provinces before and after the introduction of legislation. ${ }^{3,15,16}$ For example, several years after the introduction of legislation in Alberta and Nova Scotia, $63 \%$ to $90 \%$ of children and adolescents were observed wearing a helmet while cycling. Although these surveys, which used direct observation, are not able to assess the educational attainment of the parents, observation sites were selected randomly and the analysis controlled for neighborhood income quintile. In contrast, direct observations of children's helmet use six years after the introduction of legislation in Ontario found variation by the level of neighborhood income. ${ }^{17}$ Therefore, it remains possible that parents' attitudes and beliefs about bicycle helmet legislation are influenced by their level of educational attainment and income.

There are several other potential limitations to this study. For example, data were collected in February, a month when few children cycle. Parental perception of children's helmet use, concern for injury and support for legislation may be higher during the seasons when children typically cycle. If true, then the estimates in this study would be considered conservative. In addition, although the response rate was high, there were no data available on non-responders for comparison. Finally, we acknowledge that only parents completed this survey. Other members of society should have an opportunity to participate in this debate, particularly when considering whether legislation should be restricted to children or encompass all ages.

\section{Conclusions}

Parents of Canadian children are highly supportive of bicycle helmet legislation. This information provides a societal perspective, which may inform the current debate and may be useful for public health, knowledge translation professionals and policy makers in Canada and other countries.

\section{References}

1. Ivers R. Systematic reviews of bicycle helmet research. Inj Prev. 2007;13:190.

2. Thompson DC, Rivara FP, Thompson R. Helmets for preventing head and facial injuries in bicyclists. Cochrane Database Syst Rev. 1999;4:CD001855. 
3. Macpherson A, Spinks A. Bicycle helmet legislation for the uptake of helmet use and prevention of head injuries. Cochrane Database Syst Rev. 2007;2:CD005401.

4. Karkhaneh M, Rowe BH, Saunders LD, Voaklander DC, Hagel BE. Bicycle helmet use after the introduction of all ages helmet legislation in an urban community in Alberta, Canada. Can J Public Health. 2011;102:134-8.

5. Robinson DL. No clear evidence from countries that have enforced the wearing of helmets. BMJ. 2006;332:722-5.

6. Hagel B, Macpherson A, Rivara FP, Pless B. Arguments against helmet legislation are flawed. BMJ. 2006;332:725-6.

7. Table 2 Number and proportion of persons aged 25 to 64 by level of educational attainment and age groups, Canada, 2006 [Internet]. Ottawa (ON): Statistics Canada; [modified 2009 Nov 20; cited 2013 Feb 7]. Available from: http://www12.statcan.gc .ca/census-recensement/2006/as-sa/97-560 /table/t2-eng.cfm

8. Family income, by family type (couple families), 2009 [Internet]. Ottawa (ON): Statistics Canada; [cited 2013 Feb 7]. Available from: http://www.statcan.gc.ca /tables-tableaux/sum-som/101/cst01/famil106a -eng.htm

9. Population and dwelling counts, for Canada, provinces and territories, 2011 and 2006 censuses [Internet]. Ottawa (ON): Statistics Canada; [modified 2013 Jan 30; cited 2013 Feb 7]. Available from: http://www12.statcan.gc.ca/census-recen sement/2011/dp-pd/hlt-fst/pd-pl/Table-Tableau .cfm $?$ LANG $=$ Eng $\& \mathrm{~T}=101 \& \mathrm{~S}=50 \& \mathrm{O}=\mathrm{A}$

10. Hu X, Wesson DE, Parkin PC, Chipman ML, Spence LJ. Parental attitudes toward legislation for helmet use by child cyclists. Can J Public Health. 1993;84:163-5.

11. Dennis J, Potter B, Ramsay T, Zarychanski R. The effects of provincial bicycle helmet legislation on helmet use and bicycle ridership in Canada. Inj Prev. 2010;16:219-24.
12. Cycling death review: a review of all accidental cycling deaths in Ontario from January 1st, 2006 to December 31st, 2010. Toronto (ON): Office of the Chief Coroner for Ontario; 2012 Jun [cited 2012 Jun 21]. Available from: http://www.mcscs.jus.gov .on.ca/stellent/groups/public/@mcscs /@www/@com/documents/webasset /ec159773.pdf

13. Robinson DL. Bicycle helmet legislation: can we reach a consensus? Accid Anal Prev. 2007;9:86-93.

14. Macpherson AK, Parkin PC, To TM Mandatory helmet legislation and children's exposure to cycling. Inj Prev. 2001;7:228-30.

15. Karkhaneh M, Rowe BH, Saunders LD, Voaklander DC, Hagel BE. Bicycle helmet use four years after the introduction of helmet legislation in Alberta, Canada. Accid Anal Prev. 2011;43:788-96.

16. LeBlanc JC, Beattie TL, Culligan C. Effect of legislation on the use of bicycle helmets. CMAJ. 2002;166:592-5.

17. Macpherson AK, Macarthur C, To TM, Chipman ML, Wright JG, Parkin PC. Economic disparity in bicycle helmet use by children six years after the introduction of legislation. Inj Prev. 2006;12:231-5. 